\title{
A Case of Beals Syndrome in a Filipino Child
}

\author{
Ma-Am Joy R. Tumulak, ${ }^{1}$ Mary Ann R. Abacan ${ }^{1,2}$ and Carmencita D. Padilla ${ }^{1,2}$ \\ ${ }^{1}$ Institute of Human Genetics, National Institutes of Health, University of the Philippines Manila \\ ${ }^{2}$ Department of Pediatrics, College of Medicine and Philippine General Hospital, University of the Philippines Manila
}

\begin{abstract}
We report a case of a 12-year-old Filipino female with crumpled ears, arachnodactyly, camptodactyly, and congenital joint contractures, consistent with Beals syndrome. Marfan syndrome is a common differential diagnosis, since both are caused by mutations in two homologous genes, namely FBN1 and FBN2. Both syndromes share similar characteristics hence, it is essential to differentiate the two, since Marfan syndrome may develop fatal complications, not encountered in Beals Syndrome. Management of Beals syndrome is mainly supportive including physiotherapy and ophthalmologic and cardiovascular evaluation.
\end{abstract}

Key Words: Beals syndrome, Congenital contractual arachnodactyly, camptodactyly, FBN2 gene, Marfan syndrome

\section{Introduction}

In a paper published by Beals and Hecht, ${ }^{1}$ they described a child with multiple joint contractures, arachnodactyly, dolichostenomelia, scoliosis, and abnormality of the external ears. This condition was designated as congenital contractural arachnodactyly (CCA). Prior to the Beals and Hecht paper, patients who presented with arachnodactyly and dolichostenomelia were lumped together as part of the spectrum of Marfan syndrome. While both syndromes share certain features, peculiar to CCA is the "flattening of the helix, obliteration of the concha and complex prominent crura in the antihelix". ${ }^{2}$

The overlapping characteristics of the two syndromes can be attributed to the molecular basis of these diseases. CCA and Marfan syndrome results from mutations in two homologous genes, FBN2 and FBN1, which are highly similar but distinct genes localized to chromosomes 5q23-31 and $15 q 15-21.3$, respectively. ${ }^{3}$

The prevalence of CCA is unknown and difficult to estimate considering the overlap in phenotype with Marfan

Corresponding author: Ma-Am Joy R. Tumulak, MD

Institute of Human Genetics

National Institutes of Health

University of the Philippines Manila

623 Pedro Gil St., Ermita, Manila 1000 Philippines

Telephone: +632 5261725 local 114

Email: mrtumulak@up.edu.ph syndrome. ${ }^{4}$ However, Viljoen ${ }^{5}$ states that at least 40 families with more than 120 affected members have been reported.

Here we report the first diagnosed case of Beals syndrome in our institution.

\section{Case Report}

The proband is a 12-year-old female referred for evaluation of right knee pain. She was born to a then 31year-old G2P1 (1001) mother, full term, cephalic in presentation through spontaneous vaginal delivery at a local hospital. Her birth weight is reported at 3600 grams, birth length was unrecalled. The perinatal history is unremarkable and an ultrasound done at 6 months age of gestation was normal.

At birth, the patient was noted to have multiple ear creases and folded superior helices. There was no note of any joint contractures. At 5 years of age, she was noted to have long, slender fingers but there were no other complaints. At 11 years of age, she complained of right knee pain and there was note of scoliosis, and marked limitation in hip flexion. Her psychomotor development was at par with her peers.

She is the second child in a sibship of three, born to a healthy non-consanguineous couple of Filipino descent. No other family members share the same characteristics. On physical examination, her weight is at the $50^{\text {th }}$ percentile, height at the $75^{\text {th }}$ percentile, and head circumference at the $50^{\text {th }}$ percentile. The upper to lower segment ratio is calculated at 0.83 , while the arm span to height ratio is increased at 1.09. The patient was noted to have a flat malar area, absence of bifid uvula, presence of flattened helices (Figure 1) and, complex prominent crura giving the ears a crumpled appearance (Figure 2). There was limitation in hip flexion and note of pelvic tilt to the right (Figure 3). She exhibited arachnodactyly and camptodactyly of both hands (Figure 4). There is no note of pes planus.

Echocardiography showed normal results and ophthalmologic examinations were also normal. Skeletal survey showed dextroscoliosis of the lower thoracic and lumbar spine, elongated and slender bones, flexion deformity of the 4 th and 5th phalanges of the right hand, 3rd phalanx of the left hand and the bilateral 5th digit of the feet. The rest of the findings were unremarkable. Using the Greulich Pyle method, the patient's bone age resembled that of a 12-year-old female. 


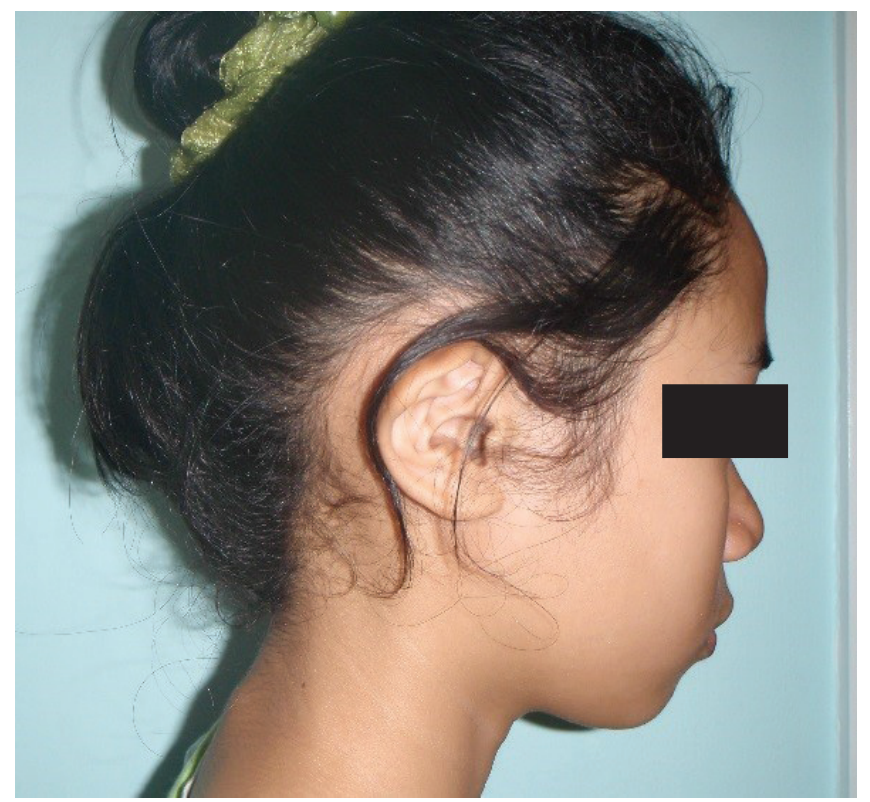

Figure 1. Flat malar area and flattened helices of the ear.

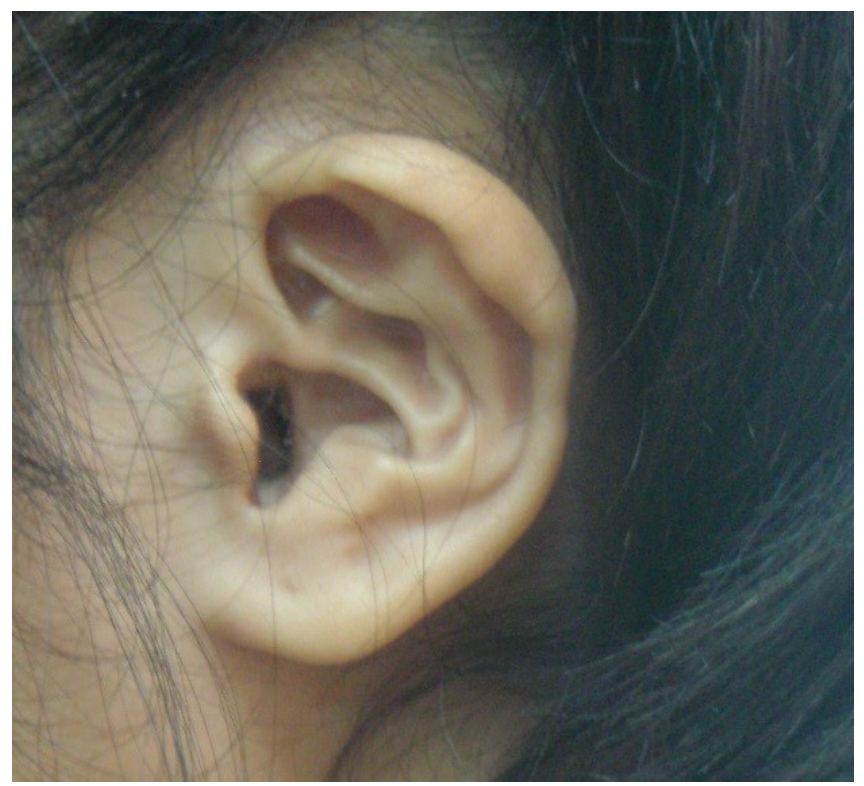

Figure 2. Prominent crura giving the ears a crumpled appearance.

\section{Discussion}

Beals and Hecht initially reported two kindreds observed by them and went on to review case reports from different countries, distilling 12 kindreds that fit into the CCA syndrome. This included a patient described by Epstein as having "hereditary dysplasia of the bone with kyphoscoliosis, contractures, and abnormally shaped ears." 5 Although the clinical features can be similar to Marfan syndrome, having multiple joint contractures and crumpled ears, in the absence of aortic root dilatation, are characteristic of Beals syndrome and rarely found in Marfan syndrome. ${ }^{4,5}$

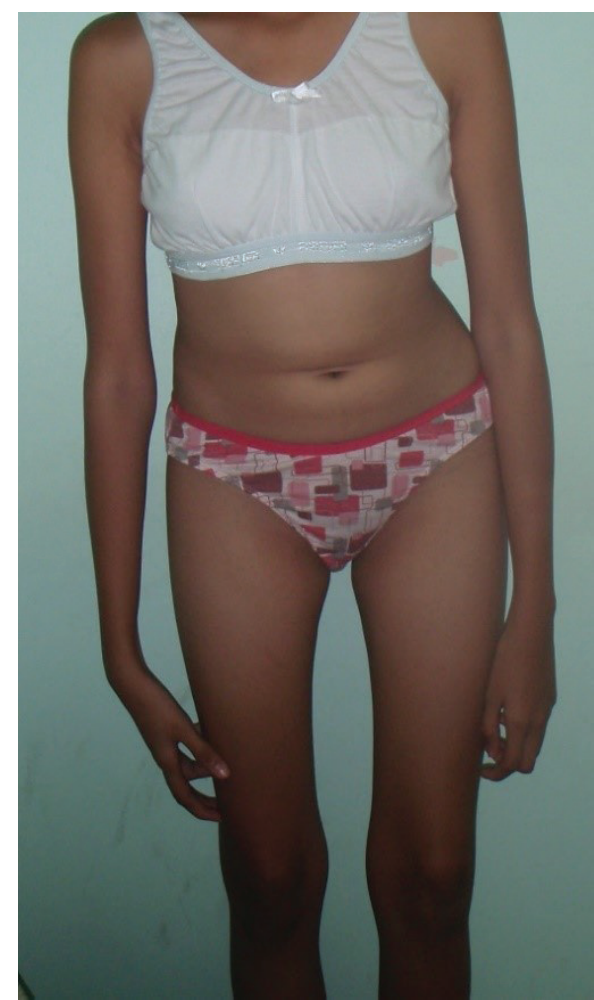

Figure 3. Pelvic tilt to the right.

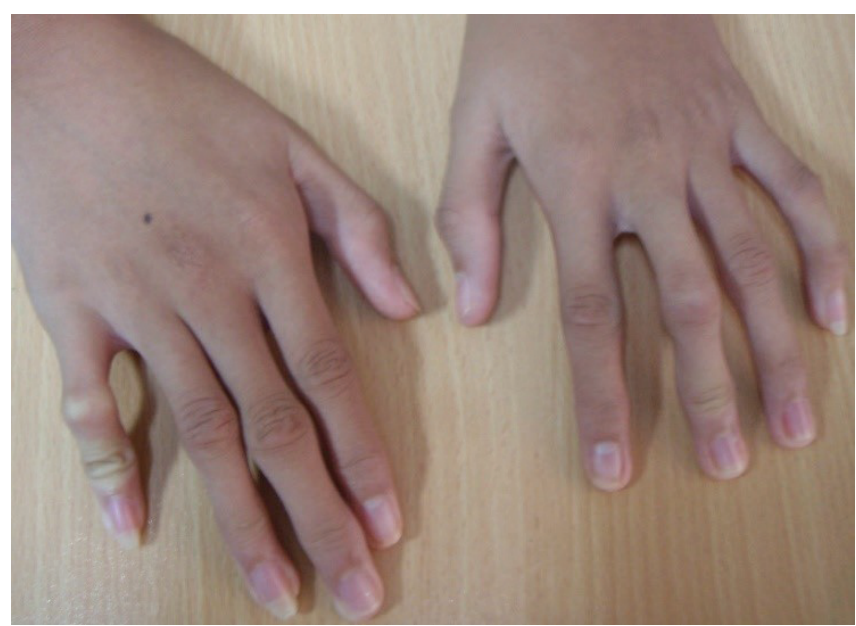

Figure 4. Arachnodactyly and camptodactyly of both hands.

The phenotypic overlap of Beals with Marfan syndrome is due to mutations in the homologous fibrillin genes. Fibrillins are large cysteine-rich extracellular matrix glycoproteins, found in all vertebrates and even in invertebrates. ${ }^{4,5}$ Mutations occur in the homologous genes, fibrillin-1 and fibrillin-2 which cause Marfan and Beals syndrome, respectively. However, due to financial constraints and unavailability of the test in the country, genetic testing for FBN1 and FBN2 mutations was not done on this patient. 
In a review by Viljoen 5 , 79 out of 104 patients were noted to have the presence of crumpled ear, 28 out of 107 individuals had limited hip extension, 85 out of 109 had camptodactyly and 94 out of 109 had arachnodactyly. Our index patient fits into the clinical spectrum of Beals syndrome having exhibited the crumpled ear appearance, limitation of motion of the hips, arachnodactyly, and camptodactyly.

Like most connective tissue disorders, one should consider ophthalmologic and cardiovascular complications in a patient. General ocular complications occur in an estimated $20 \%$ of CCA patients. ${ }^{6}$ Typical ophthalmic features include blue sclera, axial myopia, cataract, lens coloboma, ciliary body hypoplasia, and glaucoma. ${ }^{3}$ For our index patient, the ophthalmologic findings are normal, falling into the majority of patients as reported by Viljoen ${ }^{5}$ where only 9 out of 43 patients were noted to have ophthalmologic complications.

Cardiovascular complications that have been reported include mitral valve prolapse and congenital heart defects including atrial and ventricular septal defects. ${ }^{7,8}$ It must be noted however, that cardiac abnormalities are only seen in about $20 \%$ of patients, as reported by Viljoen ${ }^{5}$ where only 28 out of 103 individuals had a cardiac lesion. Our index patient falls into the majority of those with Beals syndrome who have normal cardiac findings.

Individuals with CCA are expected to be of normal mental capacity. ${ }^{3}$ However, a delay in motor development is usually common due to the contractures. In the case of our index patient, she is ambulatory but there is note of limitation of movement of the hip joint.

In light of the benign characteristic of Beals syndrome, its management is usually supportive in nature. Physiotherapy in childhood to lessen the effects of muscle hypoplasia and increase joint mobility is recommended.3,4 Due to the risk of cardiovascular and ophthalmological complications, an evaluation is done every 5 years $^{3,4}$ for early detection of aortic dilatation due to mitral valve prolapse and progressive lens subluxation. Camptodactyly may resolve in time, but some residue may always remain. ${ }^{4,5}$

Genetic counseling should be done to properly advise the family regarding the recurrence risk of this condition. It should be emphasized that although the disorder is usually inherited in an autosomal dominant transmission (50\% recurrence risk), many cases are sporadic. ${ }^{4}$ However, there are reports of germline mosaicism in the disorder.
Penetrance is complete but there is a wide variation in the expressivity of the mutant gene. ${ }^{4}$ If an identified mutation is seen in a family, prenatal testing can be done. ${ }^{4}$

\section{Conclusion}

The recognition of Beals syndrome as a condition separate from Marfan syndrome and other connective tissue disorders is of utmost importance. As Beals and Hecht has made clear, this "splitting" of Beals and Marfan Syndromes is essential to better prognostication and treatment, and to more accurate genetic counseling. ${ }^{2}$

\section{Ethical Considerations}

All photos published in this report are taken with permission from the parents of the patient.

Statement of Authorship

All authors have approved the final version of the manuscript.

Author Disclosure

All authors declared no conflict of interest.

\section{Funding Source}

None.

\section{References}

1. Beals RK, Hecht F. Congenital contractural arachnodactyly. A heritable disorder of connective tissue. J Bone Joint Surg Am. 1971; 53(5):987-93.

2. Hecht F, Beals RK. "New" syndrome of congenital contractural arachnodactyly originally described by Marfan in 1896. Pediatrics. 1972; 49(4):574-9.

3. Tungcbilek E, Alanay Y. Congenital contractural arachnodactyly (Beals syndrome). Orphanet J Rare Dis. 2006; 1:20.

4. Godfrey M. Congenital Contractural Arachnodactyly. Gene Reviews [Online]. [cited 2017 Jan]. Available from https://www.ncbi.nlm.nih. gov/books/NBK1386/.

5. Viljoen D. Congenital contractural arachnodactyly (Beals syndrome). J Med Genet. 1994; 31(8):640-3.

6. Gallego-Pinazo R, Lopez-Lizcano R, Millan JM, Arevalo JF, Mullor JL, Diaz-Llopis M. Beals-Hecht syndrome and choroidal neovascularization. Clin Ophthalmol. 2010; 4:845-7.

7. Hale MS, Rodman HD, Lipshin J. Congenital contractural arachnodactyly. West J Med. 1974; 120(1):74-6.

8. Matsumoto T, Watanabe A, Migita M, et. al. Transient cardiomyopathy in a patient with congenital contractrual arachnodactyly. J Nippon Med Sch. 2006; 73(5):285-8. 